\title{
Obituary
}

\section{Dr Alfred Ernest Tinkler 1910-1991}

Alfred Ernest Tinkler MA, MD, DPH, LLB who has died aged 80 , was in his time a distinguished venereologist, firstly in the wartime RAF, then in Cornwall and finally in Bristol.

The third son of a Quaker family from the North East of England, he was born in Liverpool in 1910 and brought up in Dublin where he was educated at St Andrews College and Trinity College, graduating first in Law and then in Medicine (LLB 1932; MB Bch, BAO 1940; MA, MD 1946; DPH (London) 1943.

He was featherweight boxing champion, British and Irish Universities 1935-36 and also active in university and Club rugby.

During the war he served with the RAF in Italy as a Squadron Leader attached to No 1 General Hospital Naples 1943-5 reaching the rank of Wing Commander. It was in this capacity that he met Alexander Fleming and embarked on his research into penicillin in the treatment of venereal diseases. This led to his postwar $\mathrm{MD}$ and a long and distinguished career in venereology.

He became a consultant in Cornwall in 1946 where he stayed for 12 years gaining an unparalleled experience of congenital syphilis which was still common in the remoter rural areas of West Cornwall at that time. He was active on many medical committees, Chairman of West Cornwall Medical Advisory Committee (1952-8) and of the Medical Planning Committee for Treliske Hospital. For many years he was either President or Chairman of Penryn Rugby Football Club.

From 1958 he was Senior Consultant and Director of Venereology to the United Bristol Hospitals and Lecturer in Venereal Disease to the University of
Bristol. He also ran the Cheltenham and WestonSuper-Mare part-time clinics. He was a member of the Medical Committee of the United Bristol Hospitals and also largely responsible for the design of the New Bristol Clinic which opened in the early 1970s. He was also chairman of a number of United Bristol Hospitals Sports Clubs (including, of course, the Rugby Club) and was first Chairman of the United Bristol Hospitals combined Sports Club-founded largely as a result of his efforts. Apart from various papers he was the author of Venereology in Modern Medicine 1975 and 1979 and Syphilis in Bailey and Love's Surgery 1975. He was Civilian Adviser in Venereology to the RAF and Air Ministry.

He was on the Council of the MSSVD 1961-64, 1967-1970 and was declared a life member of the Society in 1979. He arranged the Society's spring meeting in May 1966 and there are those who still talk of his most gracious hospitality at that time. His colleagues in Bristol will always remember his professionalism, extreme kindness (both to his patients and all levels of staff) and above all his sense of humour and gifts as a raconteur. He was a delight to work with or to meet on a social plane.

He retired in 1975 but continued to do locum work until golf took over more of his time in the 1980s. He was still playing regularly at the age of 80 and, according to his family, was particularly adept at the 19th hole where, seldom separated from his faithful pipe, he had very numerous true friends, as he had had all his life.

He is survived by his wife Rita, one daughter, two sons and seven grandchildren, and celebrated his golden wedding shortly before his death.

A N McClean 